\title{
Expression of the c-MET, HGF and VEGF biomarkers in intestinal and diffuse gastric cancer in the Brazilian population: a pilot study for the standardization of the quantitative PCR technique
}

Bianca Della Croce Vieira Cota', Karine Sampaio Lima' ${ }^{1}$, André Márcio Murad², Marcelo Antônio Pascoal Xavier³, Mônica Maria Demas Álvares Cabral ${ }^{3}$ and Luiz Gonzaga Vaz Coelho ${ }^{1,2^{*}}$

\begin{abstract}
Background: Gastric carcinoma (GC) is the third leading cause of death among malignant tumors worldwide, causing approximately 900,000 deaths/year. Changes in oncogenes that encode tyrosine kinase receptors play an important role in the pathogenesis of GC. MET gene is a proto-oncogene that encodes a tyrosine kinase receptor cMET and it is required for embryonic development and tissue repair. The hepatocyte growth factor (HGF) is the only known ligand for c-Met receptor. The MET oncogene activation suppresses apoptosis and promotes the survival, proliferation, migration, differentiation and angiogenesis of cells. Among the angiogenic factors, VEGF is the main regulator. Its biological function includes the promotion of endothelial cells mitosis to stimulate cells proliferation. These biomarkers expression in GC is relatively recent and population-based studies are required to define the expression pattern. The aim of this study was to determine qPCR technical standardization to evaluate quantitatively, in paraffin tissue samples, the presence of gene 23 expression of the MET, HGF and VEGF in diffuse and intestinal GC types.

Methods: Twenty GC patients were studied, 10 patients were intestinal-type GC (average age 72.1 years) and 10 diffuse-type (average age 50.1 years). In all patients, tissue samples were analyzed from the tumor and distant areas of the tumor tissue. The relative expressions of the tumor markers c-Met, HGF and VEGF were performed by qPCR technique by comparing tumor and non-tumoral samples and they were normalized with the GAPDH constitutive gene. Statistical analysis was performed through T-test.

Results: For c-Met, 18/20 (90\%) patients expressed the marker and 9/20 (45\%) overexpressed this gene, in which three were intestinal-type GC and six were diffuse-type GC. For HGF, only $7 / 20$ (35\%) patients expressed this gene and it was overexpressed in 4/20 (20\%), in which two were intestinal-type GC and two were diffuse-type GC. For VEGF, 20/20 (100\%) patients expressed this marker and in 12/20 (60\%) were observed overexpression, in which eight patients had diffuse-type GC and four had intestinal-type GC.

(Continued on next page)
\end{abstract}

\footnotetext{
* Correspondence: Icoelho22@gmail.com

${ }^{1}$ Alfa Institute of Gastroenterology, Clinics Hospital, Federal University of

Minas Gerais, Av. Alfredo Balena 110, $2^{\circ}$ andar, sala 208., CEP: 30130-100 Belo Horizonte, MG, Brazil

${ }^{2}$ Department of Internal Medicine, Faculty of Medicine, Federal University of

Minas Gerais, Belo Horizonte, Minas Gerais, Brazil

Full list of author information is available at the end of the article
} 
(Continued from previous page)

Conclusions: GPCR technique was standardized and suitable for expression analysis of the three biomarkers using paraffin embedded tissue samples. Further studies should be carried out to characterize the expression pattern of these biomarkers in GC in the Brazilian population.

Keywords: Gastric cancer, Stomach neoplasms, Real-Time Polymerase Chain Reaction, Proto-Oncogene Proteins cMet, Vascular Endothelial Growth Factor A

\section{Background}

Gastric carcinoma (GC) is the most frequent gastric epithelial neoplasia, responsible for $95 \%$ of malignant tumors that affect the human's stomach. Although the incidence of gastric carcinoma has been declining continuously and regularly in recent decades, it is the third cause of cancer death in the world, with more than 900,000 new cases per year [1]. In Brazil, the National Institute of Cancer (INCA) has estimated 20,520 new GC cases in the country for the year 2016, being 12,920 men and 7600 women [2].

The most commonly used classification system, with prognostic value, is the histopathological classification from Laurén [3]. According to Laurén, the neoplasias can be classified into two main types: 1-intestinal, in which there is formation of clearly identifiable glands, with varying degrees of differentiation, whose cells are large and defined, pleomorphic, with hyperchromatic nuclei, frequently exhibiting gastric wall invasion. It is observed prevalence in populations at high risk for GC and in male patients, at a more advanced age; or 2diffuse, in which consists of the proliferation of isolated cells, in signet ring, with monomorphic and regular nuclei, without glandular formation, with a tendency to accumulate intracellular mucus that infiltrates into the gastric wall individually. It affects more often low risk populations, equally to both sexes in the younger age [3-6]. The process of diffuse-type GC carcinogenesis is more associated with genetic factors, being less influenced or modulated by environmental factors than the intestinal-type GC [7]. Recently, four distinct molecular subtypes of gastric cancer have been described: the first one is the Epstein-Barr virus (EBV)-positive subtype; the second shows high microsatellite instability (MSI), where mutations tend to accumulate in repeated DNA sequences; the third and fourth subtypes have an alteration in the somatic copy number (deletion or duplication of parts of the genome). The tumors in the third subtype have a low level of somatic copy number alterations (SCNAs) and are genomically stable, and the last one is classified as chromosomally unstable, with a high level of SCNAs [8]. This classification is now believed to enable treatments to be tailored to individual patients according to the specific genetic features of their tumors.

Angiogenesis consists of the growth of new blood vessels from a pre-existing vessel through the action of an angiogenic stimulus, such as the VEGF release and other growth factors [9]. Usually, the balance between the release of pro and anti-angiogenic factors controls it. This balance can be broken into tumoral processes, in which the tumor depends on the constant formation of new vessels to insure the oxygenation and nutrients perfusion, as well as to eliminate metabolic products. Unlike the normal tissue, in which angiogenesis is strictly controlled, in neoplastic tissue it is uncontrollable and immature [10].

Genetic abnormalities, such as oncogenes activation, are also present in GC, and MET is one of them [11]. MET is a proto-oncogene, located at the chromosome 7, which encodes the receptor tyrosine kinase c-MET. The Hepatocyte Growth Factor (HGF) is the only known ligand for the c-MET receptor [12-15].

In Brazil, there are few studies on the incidence or prevalence of this proto-oncogene and its receptor. A Brazilian study, involving 482 cases of GC, analyzed 28 proteins through immunohistochemistry (IHQ), including c-Met, which was expressed in $92 \%$ of intestinal-type and $84 \%$ diffuse-type GC [16].

The improper activation of c-MET by HGF may confer proliferative, invasive, metastatic and survival ability to cancerous cells $[14,17]$. The overexpression of cMET has been correlated with the tumor invasion depth, lymph node metastasis, more advanced staging and decreased survival [17-19].

The knowledge of the expression of genes MET, HGF and VEGF becomes relevant in clinical practice, and may confer greater precision to the cancer staging and, consequently, a better definition of the patient's prognosis. The objective of the study herein was to standardize the GPCR technique to evaluate and correlate the expression of genes MET, HGF and VEGF, in paraffinembedded GC samples and non-tumoral samples.

\section{Methods \\ Samples}

A retrospective study was carried out with 20 selected cases of patients with GC diagnosed and surgically treated at Clinics Hosptital from Federal University of Minas Gerais (HC-UFMG). Paraffin-embedded tissue samples from patients submitted to total subtotal or partial gastrectomy originally stored in the Research Laboratory in Pathology 
of Gastrointestinal Tract (LP-TGI) of the Department of Pathology (APM) of HC-UFMG were used.

The GC cases were selected through histopathological slides examination by a pathologist, stained by routine staining (hematoxylin and eosin stain, $H \& E$ ), to rediagnose if there was carcinoma and to confirm the GC subtype: intestinal or diffuse [3]. Twenty staining slides representing non-tumoral adjacent gastric mucosa, away from the tumor margin, were also selected. The selected tumor areas were constituted almost exclusively of tumor cells (80-90\%) and eventually of necrosis and remaining gastric tissues (10-20\%). The non-tumoral mucosa samples were taken from areas with a distance ranging from 7 to $10 \mathrm{~cm}$ from the tumor area.

From the slides chosen, the paraffin blocks were matched and selected to compose two groups: 1) Group $\mathrm{T}$ (tumor)-20 paraffin-embedded tumor samples: ten from intestinal-type GC patients and ten from diffusetype GC patients; 2) Group NT (non-tumoral)-20 paraffin-embedded non-tumoral gastric mucosa samples from Group $\mathrm{T}$ patients, collected from gastric mucosa areas distant from the tumor.

\section{RNA extraction}

The RNA extraction protocol was performed according to the kit RecoverAll ${ }^{\text {tw }}$ Total Nucleic Acid Isolation Kit (Ambion, USA) and quantified by the Nanodrop 2000 spectrophotometer. The samples were subjected to a vacuum concentrator (Concentrator 5301, Eppendorf) for $25 \mathrm{~min}$ to increase the ribonucleic acid concentration and its quality were again quantified and analyzed by calculating the absorbance ratio at 260 and $280 \mathrm{~nm}$ (A260/280) in Nanodrop.

\section{cDNA synthesis}

The reverse transcription of RNA was carried out according to the High Capacity cDNA Reverse Transcription kit (Applied Biosystems, USA). Total RNA concentration was standardized to $300 \mathrm{ng} / 20 \mu \mathrm{L}$ for the cDNA synthesis. Thermal cycling was performed in a Veriti $^{\text {in }}$ PCR thermal cycler (Applied Biosystems, USA) under the following conditions: $25^{\circ} \mathrm{C}$ for $10 \mathrm{~min}, 37^{\circ} \mathrm{C}$ for $120 \mathrm{~min}, 85^{\circ} \mathrm{C}$ for $5 \mathrm{~min}$ and held at $4{ }^{\circ} \mathrm{C}$.

\section{Quantitative PCR}

Real-Time Quantitative PCR for gene expressions analysis was performed according to the TaqMan Gene Expression Assays (Applied Biosystems, USA) protocol. The commercially inventoried TaqMan probes used were as follows: cMET, Hs01565584_m1; HGF, Hs00300159_m1; VEGF, Hs00900055_m1; and GAPDH, Hs03929097_g1 as control. The amplification was performed in triplicate using 30 ng of cDNA by reaction on a StepOnePlus ${ }^{\text {Tat }}$ Real-Time PCR System (Applied Biosystems, USA) under the following PCR conditions: $50{ }^{\circ} \mathrm{C}$ for $2 \mathrm{~min}, 95{ }^{\circ} \mathrm{C}$ for 10 min followed by 40 cycles at $95{ }^{\circ} \mathrm{C}$ for $15 \mathrm{~s}$ and $60{ }^{\circ} \mathrm{C}$ for $1 \mathrm{~min}$. All reactions were subjected to the same conditions and normalized by the signal from the reference dye ROX passive for correction of possible reading fluctuations resulting from changes in volume and evaporation along the reaction.

The results were expressed in value of $\mathrm{Ct}$ (cycle threshold) and the arithmetic average was calculated for each sample, with data being transfered to spreadsheets for the carrying out of statistical analysis.

The housekeeping gene GAPDH was expressed in all the samples and in all the assays performed.

The RE calculation also known as fold-change was performed according to the method $2^{-\Delta \Delta C t}$. This was done for all pairs of samples (tumor and non-tumoral) for each patient. The interpretation of the RE data adopted the following rules: 1) Case $\Delta \Delta C t>0 ; \Delta C t$ (tumor) $>\Delta C t$ (non-tumoral) $\rightarrow \operatorname{RE} \quad 1 ; 2$ ) Case $\Delta \Delta C t$ $=0 ; \Delta C t$ (tumor) $=\Delta C t$ (non-tumoral) $\rightarrow \mathrm{RE}=1$; and 3 ) Case $\Delta \Delta C t \quad 0$; $\Delta C t$ (tumor) $\quad \Delta C t$ (non-tumoral) $\rightarrow$ $\mathrm{RE}>1$.

\section{Statistical analysis}

The statistical analysis of the data was performed using descriptive statistical techniques (tables and percentages). Microsoft Excel (2010) software was used to mount the database and to compare the mean values of the two sets of data (intestinal and diffuse GC subtypes) the T-test was executed through the Minitab 17 (2015) software, being considered significant statistical differences for values (p) inferior than 0.05 .

\section{Results}

Table 1 displays characteristics of all GC patients included in the study by intestinal and diffuse histologic subtypes, age and sex group, where it is shown a significant difference among the ages of the two GC subtype groups $(p<0.001)$.

Table 1 Clinical and pathological characteristics of the 20 patients studied

\begin{tabular}{lllll}
\hline $\begin{array}{l}\text { Gastric Carcinoma } \\
\text { Type }\end{array}$ & $\begin{array}{l}\text { Age average in years } \\
(\text { min-max })\end{array}$ & SD $^{\text {a }}$ & \multicolumn{2}{l}{ Sex (\%) } \\
\cline { 3 - 5 } & $50.1(32-63)^{* *}$ & 11.377 & $6(60)$ & $4(40)$ \\
\hline $\begin{array}{l}\text { Diffuse } \\
n=10)\end{array}$ & $72.1(60-86)^{* *}$ & 7.680 & $7(70)$ & $3(30)$ \\
$\begin{array}{l}\text { Intestinal } \\
(n=10)\end{array}$ & $61.1(32-86)$ & & & Male \\
$\begin{array}{l}\text { Total } \\
(n=20)\end{array}$ & & & $13(65)$ & $7(35)$ \\
\hline
\end{tabular}

a SD Standard deviation; ** $p<0.001$ 
Relative expression of biomarkers c-Met, HGF and VEGF Figure 1 exhibits the $\Delta \Delta C t$ values for c-Met, HGF and VEGF in patients with intestinal and diffuse GC types. The values above zero correspond to patients who had a greater expression of the marker in tumor sample than the non-tumoral sample.

Figure 2 shows the RE values of patients with intestinal and diffuse GC types, for the three biomarkers. The values below one correspond to the same patients who obtained $\Delta \Delta C t$ greater than zero in Fig. 1, i.e., an expression higher of the marker in tumor sample than the non-tumoral sample.

Figure 3 illustrates the difference between the relative expression (RE) means of intestinal and diffuse GC subtype groups with a $95 \%$ confidence interval $(\mathrm{CI})$ that reflects a significance level of 0.05 . In graph $\mathrm{A}$, the mean value of the relative expression of the intestinal group $(n=8)$ is 1.34 and diffuse $(n=10)$ is $1.43(p=0.874)$. In $\mathrm{B}$, the intestinal group $(n=3)$ has a mean of 1.15 and the diffuse group $(n=4)$ has a mean of $1.52(p=0.773)$. In $C$, each group has $n=10$ and two points off the chart can be observed due to being more extreme $(\mathrm{RE}=5.16$ and $R E=0.09$ ). In these circumstances, the mean value for patients in the intestinal group is 1.69 and for those in the diffuse group is 0.766 . In $\mathrm{D}$, the two extreme individual points considered outliers, resulting from a random non-identified variation were removed, remaining $n=9$ for each of the intestinal and diffuse type groups. The intestinal-type GC group presents mean expression value of 1.302 and the diffuse-type GC group, mean of $0.634(p=0.053)$.

Comparing the proportions of overexpression and normo-expression on the diffuse and intestinal GC types, statistically significant results were observed for the VEGF gene $(p=0.046)$. However, there were no significant results for the genes MET $(p=0.330)$ and HGF $(p=0.652)$.

\section{Discussion}

Our pilot study was able to assess, by the qPCR technique, the relative gene expression of three biomarkers, c-Met, HGF and VEGF between tumor and non-tumoral tissue samples of patients with intestinal and diffuse GC types. The methodology was found to be an effective procedure for this purpose, due to its specificity, efficiency (i.e. yield), and reliability, especially when it comes to paraffinembedded samples, which have a lower concentration of nucleic acid and can be accurately detected.

In contrast to $\mathrm{qPCR}$, most studies that performed the IHQ methodology do not have a consensus on the score criteria to test c-Met [15]. Furthermore, this technique has several variables involved, such as: the use of heterogeneous samples, with different tissue sections and sizes; variation between observers; a large range of primary and secondary antibodies and their particularities; staining protocols; methods used for the score; differences in the samples' processing or handling; and storage conditions. Besides, the used IHC reagents often vary their

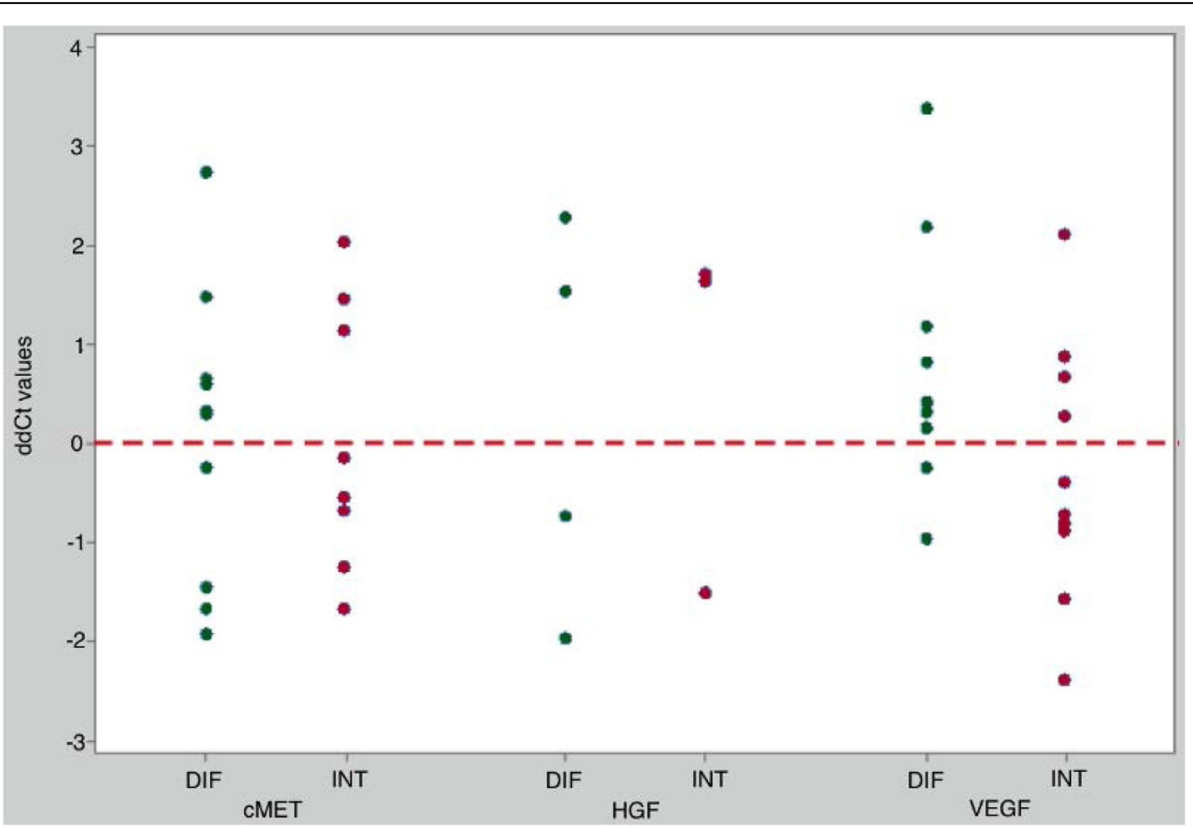

Fig. 1 Graph of $\triangle \triangle C t$ (ddCt) values for c-MET, HGF and VEGF, in patients with gastric carcinoma. The values above zero correspond to patients who had a higher expression in tumor sample, where $\Delta \Delta C t>0=\Delta C$ (tumor) $>\Delta C$ ( (non-tumoral) and $\Delta \Delta C t<0=\Delta C$ ( (tumor) $<\Delta C t$ (non-tumoral). INT = intestinal; DIF = diffuse 


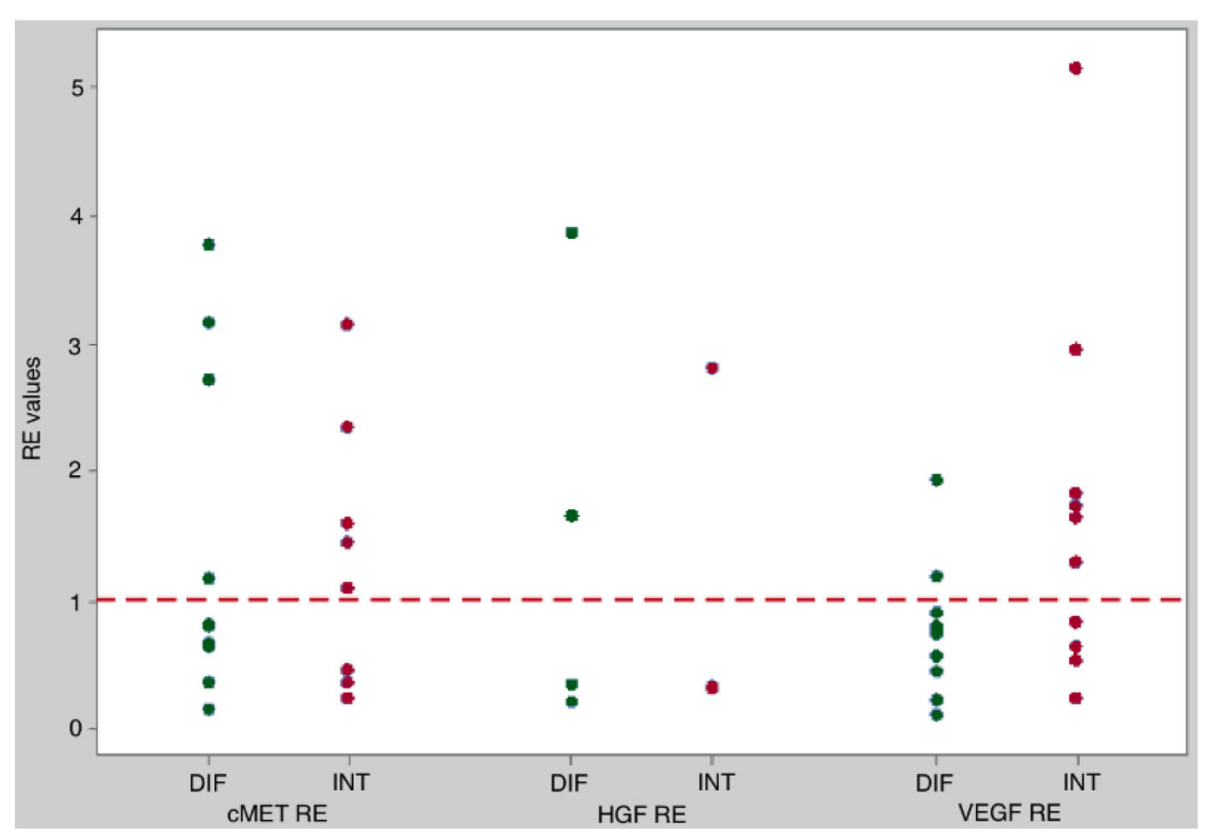

Fig. 2 Graph of the RE for c-MET, HGF and VEGF, in patients with gastric carcinoma. The RE values below one correspond to patients who had a higher expression in tumor sample, where $\mathrm{RE}>1=\Delta C t$ (tumor) $<\Delta C$ ( INT = intestinal; DIF = diffuse

specificity and sensitivity [15]. All these factors have implications for the use of c-Met and its ligand in the IHC method, which made us to opt for the qPCR technique for the pilot study, instead of using the IHQ that was also an option, considering our small sampling and poor amount of tissue in the paraffin blocks to standardize more than one procedure.

Our findings regarding the patients' average age with intestinal-type GC (72.1 years) and diffuse type (50.1 years) is consistent with what was described by Laurén, according to whom there is a higher incidence of intestinal-type GC in more advanced age patients [3].

Among the three markers, HGF was the one which showed the lowest gene expression in our samples, i.e., in only seven out of the 20 patients. In the cases of diffuse-type CG $(n=4)$, a higher expression of the biomarker was observed than in those of intestinal type ( $n$ $=3)$, but this difference was not significant $(p=0.773)$. In the study of Amemiya et al. [20] 40 patients with GC were analyzed by IHC. This result suggests that HGF produced by tumor cells induce their own proliferative activity via autocrine. Whereas regarding the stomach stromal cells, strong HGF marking was observed in all the patients analyzed. This observation suggests that in gastric cancer, the HGF production through the stromal cells stimulates the cells proliferation and migration through paracrine activity. In agreement with these findings, another study that used IHC in 100 GC samples, it was observed that the HGF was predominantly expressed in the tumor cells cytoplasm, indicating a possible autocrine signaling. The same authors also used qPCR for analysis of relative expression and obtained as a result a correlation of HGF expression with tumoral progression. The HGF expression was significantly higher in patients with peritoneal dissemination than in those without the dissemination and it was associated with a reduction in survival and a worse prognosis [17].

Concerning the c-Met analysis performed in this study, its expression was observed in $90 \%(18 / 20)$ of the cases. Out of these 18 patients, eight of them had intestinal-type GC and 10 diffuse-type GC. There was a higher relative expression tendency for the diffuse type, but not significant $(p=0.874)$. According to Tahara [21], the carcinogenesis of intestinal and diffuse types exhibits different genetic pathways, being the diffuse type the one with higher genetic instability and greater oncogenes amplification, such as the c-Met. Lee et al. [22] also found a higher c-Met expression in the diffuse-type GC, however, the protein expression was analyzed by immunohistochemistry. In it, 438 patients with GC were analyzed and a statistical significance was found in c-Met expression among the histological types ( $p$ 0.001). Out of the cases $(n=10)$ which resulted in three crosses $(++$ +), 70\% was diffuse-type GC and 30\% intestinal-type GC and had a lower survival when compared to patients with negative marking. Janjigian et al. [23] analyzed 15 GC samples by qPCR and c-Met expressions were found significantly higher in tumors than in normal tissues 


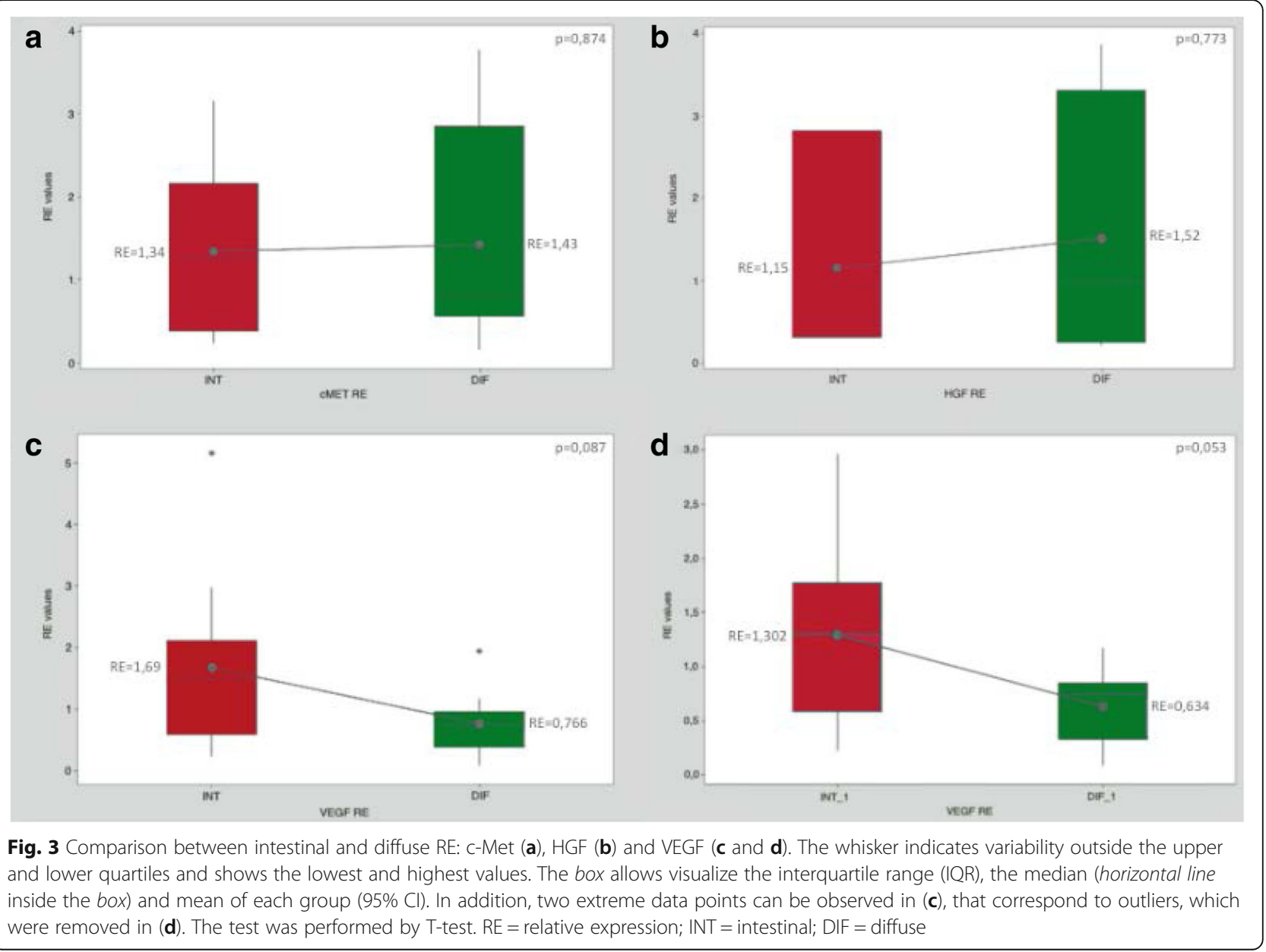

and, when comparing this expression levels between the two GC subtypes, the intestinal type was the one which showed significantly higher expression.

Although many investigators suggest that c-Met overexpression plays a critical role in GC progression and patients' survival, there are still no exact criteria to perform the techniques and the results are controversial [24].

Our findings on the relative expression of c-Met and HGF were not similar in patients, even though there was a receptor and its respective ligand. While 18 patients expressed c-Met, only seven patients expressed HGF. One suggested hypothesis would be the trans-activation or cross-talk, mechanism by which a ligand indirectly activates a tyrosine-kinase receptor for which it is not a direct agonist. The c-Met receptor is the cross-talk target by some binders, being one of them the Transforming Growth Factor-a (TGF-a) through the Epidermal Growth Factor Receptor (EGFR) [25]. Jo et al. [26] observed that in epithelial cells in the rats' liver, which expressed constitutively TGF-a, c-MET was continually phosphorylated, even in the absence of their ligand HGF. Then, they proposed to test the cross-talk between
EGFR/TGF- $a$ and c-Met/HGF in cell lines of human hepatocellular carcinoma and squamous cell carcinoma. In the study, the exposure to TGF-a and exogenous EGF increased the c-Met phosphorylation, which was inhibited using antibodies anti-TGF-a and/or EGFR. This result indicated that the c-Met constitutive phosphorylation, in the cell lines tested, was due to the cross-talk via EGFR.

This type of oncogenic MET signaling, HGF-independent activation, is attributed to gene amplification and can lead to EGFR resistance [27]. Antibodies and small-molecule inhibitors that target the $M E T$ signaling prevent the interaction between ligand and its receptor by blocking down the stream signaling. Another way to block the downstream signaling is by using $M E T$ knockdown through RNA interference. They are designed to target the active site in the intracellular domain of the receptor c-Met and inhibit its phosphorylation, thus they are able to restrain both liganddependent and ligand-independent MET activation [27].

Among the markers tested, VEGF was the only marker expressed in all the 20 samples $(100 \%)$ in addition to the higher relative expression result, statistically significant, in diffuse-type GC $(p=0.046)$. Such findings could be 
related to the natural history and biological behavior of this tumor type, which, due to being more aggressive than the intestinal-type GC, would lead to a greater neurovascular formation [4].

Correa proposed, in 1992, that the gastric carcinogenesis is a process that involves a sequence of histological changes that lead to gastric adenocarcinoma of intestinal type. Among these steps are chronic gastritis, atrophy, intestinal metaplasia and dysplasia, being these lesions associated with $H$. pylori infection. Whereas the diffuse-type $\mathrm{GC}$ is not associated to infection and it is possible to emerge in the gastric mucosa that contains a large number of little-differentiated cells (but not involving a specific standard of carcinogenesis [28]. Therefore, the nontumoral adjacent tissue undergoes greater genetic and epigenetic changes in the intestinal type than in the diffuse one, making the difference between biomarkers in nontumoral and tumoral tissue be larger in diffuse type.

Badescu et al. [12] studied 28 patients with GC, whose biopsies were processed in paraffin and IHQ was performed with anti-VEGF antibody, having normal gastric mucosa samples as control. Among the $28 \mathrm{GC}$ samples, 10 of them were diffuse type and 18 were intestinal type. The immune reaction was positive for VEGF in $80 \%$ (8/ 10) of the cases of diffuse-type GC and $55.5 \%(10 / 18)$ of the cases of intestinal-type GC. The diffuse-type GC is a histological form associated to intense angiogenic activity and the results of this study suggest that the more intense the angiogenesis in the diffuse type, the greater the metastatic potential is than when compared to the intestinal type.

Some limitations of our study should be highlighted. Due to being a pilot study, the same has limitations inherent to its own nature, as a small sampling. Besides, the employment of paraffin-embedded samples resulted in low concentration of nucleic acids, leading to a need for multiple extractions to obtain the required concentration to the research, being the use of fresh samples more favorable. Another disadvantage was the absence of a second study methodology to analyze the protein expression levels of the same biomarkers to promote the correlation between the mRNA expression and the corresponding protein level, as a result of insufficient amount of tissue in the paraffin blocks. However, in a further study with a larger number of samples, comparisons will be made between mRNA expression and its protein using different methodologies. The fourth and final restriction factor was the use of non-tumoral adjacent tissue samples of GC patients as control instead of considering the use of healthy patients samples.

\section{Conclusion}

Our results demonstrate that the $\mathrm{qPCR}$ technique is feasible for the expression analysis of the genes MET,
HGF and VEGF in the paraffin-embedded surgical samples of intestinal and diffuse GC subtypes. Among them, the results suggest a greater expression of the three genes in the diffuse-type GC, although not statistically significant.

Further studies with a larger sample of cases must be performed to better characterize the pattern of expression of these biomarkers in human GC in the Brazilian population.

\section{Abbreviations \\ APM: Department of Pathology; cDNA: Complementary deoxyribonucleic acid; CG: Gastric carcinoma; CT: Cycle threshold; Dif: Diffuse; \\ DNA: Deoxyribonucleic acid; DNase: Desoxirribonuclease; EBV: Epstein-Barr virus; EGF: Epidermal Growth Factor; EGFR: Epidermal Growth Factor Receptor; GAPDH: Glyceraldehyde 3-phosphate dehydrogenase; H\&E: Hematoxylin and eosin; H. pylori: Helicobacter pylori; HC: Clinics Hospital; HGF: Hepatocyte Growth Factor; IAG: Alfa Institute of Gastroenterology; IHQ: Immunohistochemistry; INCA: National Institute of Cancer; Int: Intestinal; LP-TGI: Research Laboratory in Pathology of Gastrointestinal Tract; min:: Minutes; min-max: Minimum-maximum; mRNA: Messenger ribonucleic acid; MSI: Microsatellite instability; ng: Nanogram; NT: Non-tumoral group; PCR: Polymerase Chain Reaction; qPCR: Quantitative Polymerase Chain Reaction; RE: Relative expression; RNA: Ribonucleic acid; RT: Reverse transcriptase; SCNAs: Somatic copy number alterations; SD: Standard deviation; sec: Seconds; T: Tumor group; Temp: Temperature; TGF- a: Transforming growth factor alfa; UFMG: Federal University of Minas Gerais; USA: United States of America; VEGF: Vascular Endothelial Growth Factor; Mg: Microgram; $\mu \mathrm{L}$ : Microliter}

\section{Acknowledgements}

The study was supported by Conselho Nacional de Desenvolvimento Científico e Tecnológico (CNPq/Brazil), and Fundação de Amparo à Pesquisa do Estado de Minas Gerais (FAPEMIG/Brazil).

\section{Funding}

The study was financially supported by Conselho Nacional de Desenvolvimento Científico e Tecnológico (CNPq: 471138/2013-4) and Fundação de Amparo à Pesquisa do Estado de Minas Gerais (FAPEMIG: CDSPPM-00522-15).

\section{Availability of data and materials}

The datasets and materials used and/or analyzed during the current study will be available by the corresponding author upon reasonable request.

\section{Authors' contributions}

BDCVC: data collection; lab research; statistical analysis; discussion of the results; text edition. KSL: lab research, results discussion; text edition. AMM: contributed to the basic idea and conception of the project. MAPX: contributed to the data collection and performed the slides histological examination. MMDAC: contributed to the statistical analysis. LGVC: contributed to the conception, study design, text edition. All authors read and approved the final manuscript.

\section{Competing interests}

The authors declare that they have no competing interests. We attest to the fact that all authors listed on the title page have contributed significantly to the study, have read the manuscript, attested to the validity and legitimacy of the data and its interpretation, and agreed to its submission to the Applied Cancer Research.

\section{Consent for publication}

Not applicable.

\section{Ethics approval and consent to participate}

The Research Ethics Committee of the Federal University of Minas Gerais approved this research project (CAAE: 16476713.0.00000.5149) on July 03, 2013. 


\section{Publisher's Note}

Springer Nature remains neutral with regard to jurisdictional claims in published maps and institutional affiliations.

\section{Author details}

'Alfa Institute of Gastroenterology, Clinics Hospital, Federal University of Minas Gerais, Av. Alfredo Balena 110, $2^{\circ}$ andar, sala 208., CEP: 30130-100 Belo Horizonte, MG, Brazil. ${ }^{2}$ Department of Internal Medicine, Faculty of Medicine, Federal University of Minas Gerais, Belo Horizonte, Minas Gerais, Brazil. ${ }^{3}$ Department of Pathology, Faculty of Medicine, Federal University of Minas Gerais, Belo Horizonte, Minas Gerais, Brazil.

Received: 26 January 2017 Accepted: 5 May 2017

Published online: 04 July 2017

\section{References}

1. Parkin D, et al. Global cancer statistics. CA Cancer J Clin. 2005;55:74-108.

2. Instituto Nacional do Câncer. Inca. Estimativa/2014. Disponível em http:// www1.inca.gov.br. Acesso em 14 Jan 2016.

3. Laurén P. The Two Histological Main Types of Gastric Carcinoma: Diffuse and So-Called Intestinal-Type Carcinoma. An Attempt at a Histo-Clinical Classification. Acta Pathol Microbiol Scand. 1965:64:31-49.

4. Laurén P. Histogenesis of intestinal and diffuse types of gastric carcinoma. Scand J Gastroenterol Suppl. 1991;180:160-4.

5. Laurén P, Nevalainen T. Epidemiology of intestinal and diffuse types of gastric carcinoma. A time-trend study in Finland with comparison between studies from high- and low-risk areas. Cancer. 1993;71:2926-33.

6. Correa P, Piazuelo M. Natural history of Helicobacter pylori infection. Dig Liver Dis. 2008:40:490-6.

7. Tahara E. Genetic pathways of two types of gastric cancer. IARC Sci Publ. 2004;157:327-49.

8. TCGA. Comprehensive molecular characterization of gastric adenocarcinoma. Nature. 2014:513:202-9.

9. Yoshida WB. Angiogenesis, arteriogenesis and vasculogenesis: treatment of the future for lower limb critical ischemia? J Vasc Bras. 2005:4:316-8.

10. Folkman J, Long DM Jr, Becker FF. Growth and metastasis of tumor in organ culture. Cancer. 1963;16:453-67.

11. Catalano V, Labianca R, Beretta GD, et al. Gastric cancer. Crit Rev Oncol Hematol. 2009:71:127-64.

12. Badescu A, Georgescu CV, Vere CC, et al. Correlations between Her2 oncoprotein, VEGF expression, MVD and clinicopathological parameters in gastric cancer. Rom J Morphol Embryol. 2012;53(4):997-1005.

13. Sierra J, Tsao MS. c-MET as a potential therapeutic target and biomarker in cancer. Ther Adv Med Oncol. 2011;3:S21-35.

14. Gentile A, Trusolino L, Comoglio PM. The Met tyrosine kinase receptor in development and cancer. Cancer Metastasis Rev. 2008;27:85-94.

15. Hack S, Bruey JM, Koeppen H. HGF/MET-directed therapeutics in gastroesophageal cancer: a review of clinical and biomarker development. Oncotarget. 2014;5(10):2866-80.

16. Begnami MD, Fregnani $\mathrm{JH}$, Brentani $\mathrm{H}$, et al. Identification of protein expression signatures in gastric carcinomas using clustering analysis. J Gastroenterol Hepatol. 2012;2(2):378-84.

17. Toiyama Y, Yasuda H, Saigusa S, et al. Co-expression of hepatocyte growth factor and c-Met predicts peritoneal dissemination established by autocrine hepatocyte growth factor/c-Met signaling in gastric cancer. Int J Cancer. 2012;130:2912-21.

18. Nakajima M, Sawada $H$, Yamada $Y$, et al. The prognostic significance of amplification and overexpression of c-met and c-erb B-2 in human gastric carcinomas. Cancer. 1999;85(9):1894-902.

19. Tanigushi K, Yonemura Y, Nojima N, et al. The relation between the growth patterns of gastric carcinoma and the expression of hepatocyte growth factor receptor (c-met), autocrine motility factor receptor, and urokinasetype plasminogen activator receptor. Cancer. 1998;82(11):2112-22.

20. Amemiya H, Menolascino F, Peña A. Papel de la expresión del receptor cMet em la progresión del câncer gástrico. Invest Clin. 2010;51(3):369-80.

21. Tahara E. Genetic alterations in human gastrointestinal cancers. The application to molecular diagnosis. Cancer. 1995;75:1410-7.

22. Lee H, Kim MA, Lee HS, et al. MET in gastric carcinomas: comparison between protein expression and gene copy number and impact on clinical outcome. Br J Cancer. 2012;107:325-33.
23. Janjigian $Y Y$, Tang LH, Coit DG, et al. MET Expression and Amplification in Patients with Localized Gastric Cancer. Cancer Epidemiol Biomarkers Prev. 2011;20:1021-7

24. Inokushi $\mathrm{M}$, Otsuki $\mathrm{S}$, Fujimori $\mathrm{Y}$, et al. Clinical significance of MET in gastric cancer. World J Gastrointest Oncol. 2015;7(11):317-27.

25. Huang TJ, Wang JY, Lin SR, et al. Overexpression of the c-met Protooncogene in Human Gastric Carcinoma- correlation to clinical features. Acta Oncol. 2001;40(5):638-43.

26. Jo M, Stolz DB, Esplen JE, Dorko K, et al. Cross-talk between epidermal growth factor receptor and c-Met signal pathways in transformed cells. J Biol Chem. 2000:275(12):8806-11.

27. Kawakami H, Okamoto I. MET-targeted therapy for gastric cancer: the importance of a biomarker-based strategy. Gastric Cancer. 2016;19:687-95.

28. Correa P. Human gastric carcinogenesis: a multistep and multifactoria process-First American Cancer Society Award Lecture on Cancer Epidemiology and Prevention. Cancer Res. 1992;24:6735-40.

\section{Submit your next manuscript to BioMed Central and we will help you at every step:}

- We accept pre-submission inquiries

- Our selector tool helps you to find the most relevant journal

- We provide round the clock customer support

- Convenient online submission

- Thorough peer review

- Inclusion in PubMed and all major indexing services

- Maximum visibility for your research

Submit your manuscript at www.biomedcentral.com/submit
Biomed Central 